\title{
NEW PRODUCT MANAGEMENT \\ sciendo \\ WITH THE APPLICATION OF THE MANUFACTURING \\ COMPANY PROJECT PORTFOLIO \\ MANAGEMENT CONCEPT
}

doi:10.2478/mape-2018-0077

Date of submission of the article to the Editor: 05/2018

Date of acceptance of the article by the Editor: 07/2018

MAPE 2018, volume 1, issue 1, pp. 613-619

\author{
Dr Anna Musioł-Urbańczyk Eng. \\ Dr Barbara Sorychta-Wojsczyk Eng. \\ Silesian University of Technology, Poland
}

\begin{abstract}
The article presents the project portfolio management system in a selected manufacturing company operating in the advertising industry in the field of new product project management. It discusses individual elements and structure of the system, and the scope of procedures performed within the system.
\end{abstract}

Keywords: project, portfolio of projects, project management, project portfolio management

\section{INTRODUCTION}

The project portfolio management system in the analysed company defines the main principles and applicable standards in project management on the basis of a specific methodology to ensure effectiveness of the implementation of undertakings having the characteristics of projects. Projects are interpreted as undertakings aimed at creating value for the company and taking advantage of business opportunities consistent with the strategy. This project portfolio management system concept was developed based on traditional project management methods PRINCE2 and PMI (PRINCE2, 2009); (PMBook, 2008) because the number of non-IT companies applying agile project management (APM) in practice is significantly low (Spałek, 2016). Given the volatile environment, increasing competition in the advertising industry, and more and more new customers' requirements, the company needs to continuously implement new products and improve the existing ones. This requires allowing for projects aimed at the implementation of new products within the portfolio of projects of the company.

The company to be analysed is a modern company operating on the Poland's advertising market since 1998. It provides professional visual advertising element design and production services. The basic range of products can be classified into 9 groups of goods, such as illuminated advertising, LED systems, spatial advertisement, large format printing, advertising on vehicles, printing services, signs and banners, web design, billboards and freeboards.

The company puts a strong emphasis on constant attention to the attractiveness of the commercial offer, in particular the quality of offered products, timely delivery of orders and deliveries, favourable business terms, continuous development of the commercial offer, and professionalism of the team of technical and commercial advisors. The employees' experience, flexibility, technical and negotiation skills enable the company to the meet very strict requirements posed by customers.

Strategic objectives set by the company for the next three years include: annual participation in trade fairs, further intensification of exports, intensification of sales in the most industrialised areas of the country, organisation of new, semi-annual promotions for customers, and preparation to compete with the largest companies on the market. 
In the context of so specified business objectives, it appears necessary to develop and implement a project portfolio management system (PPMS in short) that would allow for the management of new products.

The purpose of this article is to present the concept of a project portfolio management system in a manufacturing company, allowing for the elements and the structure of the system, and the procedures implemented within the system.

\section{RESEARCH METHODOLOGY}

To accomplish the purpose of the article, the authors carried out some research into the literature in the field of project portfolio management and project management, an analysis of the company documentation, including the management system used, executed contracts and orders. Moreover, the authors carried out an analysis of undertakings completed in the years 2016-2018, they interviewed the management board and the employees of the company, and they observed and actively participated in project planning and implementation. Table 1 shows the research procedure.

Table 1

Research procedure

\begin{tabular}{|l|l|l|l|}
\hline \multicolumn{3}{|l|}{$\begin{array}{l}\text { Purpose of research: development and implementation of a project portfolio management system allowing for new } \\
\text { product management }\end{array}$} \\
\hline No. & \multicolumn{1}{|c|}{ Research stage } & \multicolumn{1}{|c|}{ Applied research tools } & \multicolumn{1}{c|}{ Research result } \\
\hline 1. & Literature study & $\begin{array}{l}\text { critical analysis of literature, } \\
\text { web / desk research }\end{array}$ & $\begin{array}{l}\text { level of knowledge of project } \\
\text { portfolio and project } \\
\text { management }\end{array}$ \\
\hline 2. & $\begin{array}{l}\text { Selected enterprise diagnosis and } \\
\text { analysis }\end{array}$ & $\begin{array}{l}\text { analysis of company } \\
\text { documents (strategy, } \\
\text { balance sheets, contracts, } \\
\text { orders), SWOT, Porter's 5 } \\
\text { forces, Ishikawa diagram }\end{array}$ & $\begin{array}{l}\text { evaluation of company } \\
\text { condition, rationale to } \\
\text { develop PPMS }\end{array}$ \\
\hline 3. & $\begin{array}{l}\text { Analysis and evaluation of projects in the } \\
\text { company in terms of value, number of } \\
\text { persons involved, duration, complexity, } \\
\text { and level of innovation } \\
\text { observation, statistical } \\
\text { analysis }\end{array}$ & $\begin{array}{l}\text { project classification, factors } \\
\text { affecting success and failure } \\
\text { of projects }\end{array}$ \\
\hline 4. & PPMS development & \multicolumn{2}{|c|}{ Recommendation regarding PPMS effective implementation } \\
\hline \multicolumn{3}{|c|}{} \\
\hline
\end{tabular}

With respect to the so-developed research procedure, the following research questions were formulated: Is there a need to develop and use a project portfolio management system in the enterprise? What benefits does the use of the project portfolio management system provide the enterprise with? Is the use of this system permitted by the corporate culture?

\section{RATIONALE TO DEVELOP A PROJECT PORTFOLIO MANAGEMENT SYSTEM IN THE ENTERPRISE}

Based on the literature study (Trocki, 2012; Kozarkiewicz, 2012; Kerzner, 2005; SońtaDrączkowska, 2012) carried out, it may be concluded that theorists and practitioners have been increasingly more interested in the project portfolio management approach in recent years. Project portfolio management is a very important element connecting the organisational strategy with the individual project management process. It is also referred to as the missing link between the strategy and the company's project implementation plan (Spałek and Bodych, 2012). A portfolio of projects is a collection of projects (time-limited projects, projects implemented to create a unique product, service or result), programmes and other works grouped together to enable effective management of those works with a view to accomplishing strategic business objectives (PMBook, 2008).

A portfolio of projects is also defined as a view of projects, programmes and other activities related to the works carried out within the organisation (Spałek and Bodych, 2012). Projects 
and programmes constituting a portfolio may, although they do not need to, be interdependent or directly related. A portfolio comprises both projects and programmes currently pursued, both at the stage of planning and execution, draft projects pending authorisation, and temporarily suspended projects that may be continued in the future (Stawicki, 2009).

A critical analysis of the literature in the field of project management and project portfolio management makes it possible to realise that many publications emphasise that in order to avoid a material error, consisting in confusing project portfolio management with multiple projects management one may not use approaches and techniques typical of single project management at the level of a collection of projects. Project portfolio management is aimed at ensuring a greater total value created throughout the portfolio than the total of values created by each project implemented individually.

The enterprise analysed is planning and carrying out numerous undertakings having the characteristics of projects. A vast majority of them is customer orders, but the enterprise is also undertaking measures aimed at developing and implementing new products to be offered to customers and to ensure continuous development. This requires significant financial investments and involvement of a great number of people. At present, the company lacks a uniform project development and monitoring system, nor are there any rules regarding project management knowledge and experience collection. This results in the employees making the same mistakes on different projects, in the dilution of responsibility for the implementation of individual tasks within a project, in project duration extensions and overspending, and the project related risk is not managed, either. the identification of risks that have occurred in the past during the various stages of the projects, can contribute to more effective risk management during the current and future projects (Gembalska-Kwiecień, 2017). PPMS development and implementation within the company will make it possible to:

1. coordinate management of projects of importance from the strategy perspective;

2. apply uniform rules and procedures to the project management process;

3. standardization of methods and tools in project management contribute for cooperation of contractors (Spałek, 2014);

4. use a system to monitor and control implementation of all projects;

5. collect and store knowledge of projects currently and already carried out (successfully completed and abandoned ones);

6. provide project managers and teams with tools facilitating project management, collect and disseminate project management knowledge.

In conclusion, the enterprise analysed ought to provide the enterprise management system with conditions facilitating project portfolio management that will be provided for in the project portfolio management system. Such an approach will make it possible to avoid the employees' significant objection to the application of procedures provided for in the system proposed.

\section{PROJECT PORTFOLIO MANAGEMENT SYSTEM IN THE ENTERPRISE}

The project portfolio management system in the enterprise selected covers:

a) project portfolio development process;

b) project portfolio monitoring and reporting process;

c) project, including new product project, management process.

The main principle of the project portfolio management concept is to accomplish strategic objectives. The developed corporate strategy often features numerous strategic objectives which ought to be evaluated in the course of the project portfolio development in order to prioritise them. Figure 1 shows the project portfolio development process in the enterprise selected.

In the company analysed, implementation of the strategic objectives involves development and implementation of new products. Given the strategic assumptions according to which the company wishes to market new products, the project portfolio development process needs to allow for both new product projects and other projects implementation of which will provide the 
company with funds to finance its current operations as well as the operations related to the development and implementation of new products. It is therefore necessary to identify project initiatives based on the strategy, to investigate and analyse expectations and needs of existing and new customers, orders and contracts. All project initiatives need to be evaluated according to specific criteria in order to pre-select project initiatives to be then defined and provided with a business case. On the basis of the developed business cases regarding individual projects and allowing for the available budget capacities of the company, one can develop an initial portfolio of projects.

The next step, related to the prioritisation and balancing of the portfolio of projects, involves activities aimed at identifying the optimum portfolio of projects, allowing for such factors as the costs involved, the probability of success, the level of innovation, and the expected revenues /benefits. Based on that, various project portfolio versions will be developed. An analysis of the developed versions will enable the company management to decide on the final shape of the portfolio.

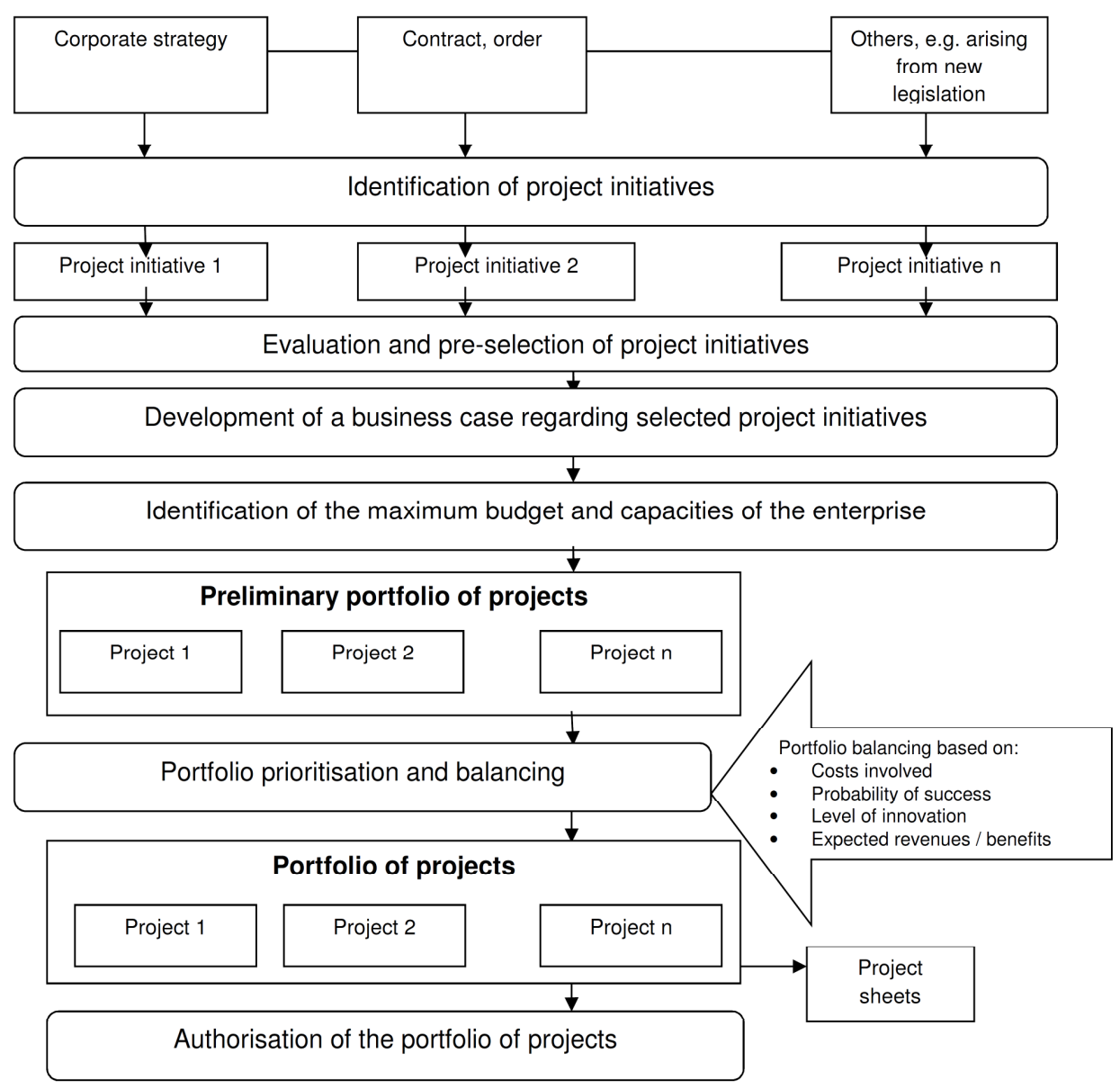

Fig. 1. Project portfolio development process in the enterprise selected

Implementation of the project portfolio involves the monitoring and controlling of individual projects implementation, including projects of new products. The project implementation monitoring and controlling process involves benchmarking of plans against actual implementation, an analysis of deviations, development of reports, communication and provision of information on the project implementation status. 


\section{ORGANISATIONAL STRUCTURE OF THE PROJECT PORTFOLIO MANAGEMENT SYSTEM IN THE ENTERPRISE}

The company analysed operates as a limited liability company, and it employs approx. 50 people. It has the most modern technical infrastructure in Poland which enables high dynamics of development. The organisational structure of the company comprises the management board, the production department, the design department, the sales department, the cutting and fitting department, the paint shop, the human resources department, and the secretariat. To ensure effective implementation of a project portfolio management system in the enterprise analysed, its organisational structure ought to comprise a Project Director, a Project Department, Project Managers and project team members.

The Project Director position ought to be held by the president of the management board directly supervising the planning, implementation and monitoring of every project undertaken within the enterprise analysed. He/She is responsible for the planning and launching of projects, appointing of project managers and approval of project team members, and controlling the work of project managers.

The company's Project Department reports directly to the president of the management board, and supports project managers. It is an advisory and controlling body on every project. Its responsibilities include the monitoring of project implementation within the company, support in crisis situations arising in the course of project implementation, project reporting, providing information to the Project Director on the need to launch a project, and the closing of the project.

The Project Manager is appointed by the Project Director, and they are responsible for the development of a project plan and for the monitoring of its implementation. Moreover, their responsibilities include development of the business case and implementation schedule, appointment of project team members, communication with project shareholders, risk management and the closing of the project.

The Project Team is appointed by the Project Director, as requested by the Project Manager. It comprises company employees and subcontractors.

\section{NEW PRODUCT PROJECT MANAGEMENT - IMPLEMENTATION PROCEDURES}

Project management within the company covers the following stages: project setting, project planning, project implementation and controlling, and project closing.

The project setting stage consists in deciding on the commencement of project implementation, identifying project requirements, appointing the project manager, and establishing a project team.

The project planning stage consists in developing a project plan that covers: work division structure (WDS), shareholder analysis, implementation schedule, inclusive of milestones, resource allocation to tasks, communication plan, budget, and risk analysis.

The project implementation and controlling stage cover implementation of tasks arising from the plan, and controlling of compliance with the plan to accomplish the project objectives.

The project closing stage consists in developing a final report and accepting a product project. In order to ensure effective project implementation within the enterprise analysed, implementation procedures in the form of process maps, implemented by the project team, have been developed. Figure 2 shows the application of procedures at individual stages of the new product project management process. The following four main procedures can be distinguished:

- project setting procedure;

- project planning procedure;

- project implementation and controlling procedure;

- project closing procedure. 
The main procedures require completion with detailed procedures, i.e.:

- ordering procedure;

- project team establishment procedure;

- prototyping procedure;

- project scheduling procedure;

- project resource allocation procedure;

- production development procedure;

- project budget development procedure;

- project risk management procedure.

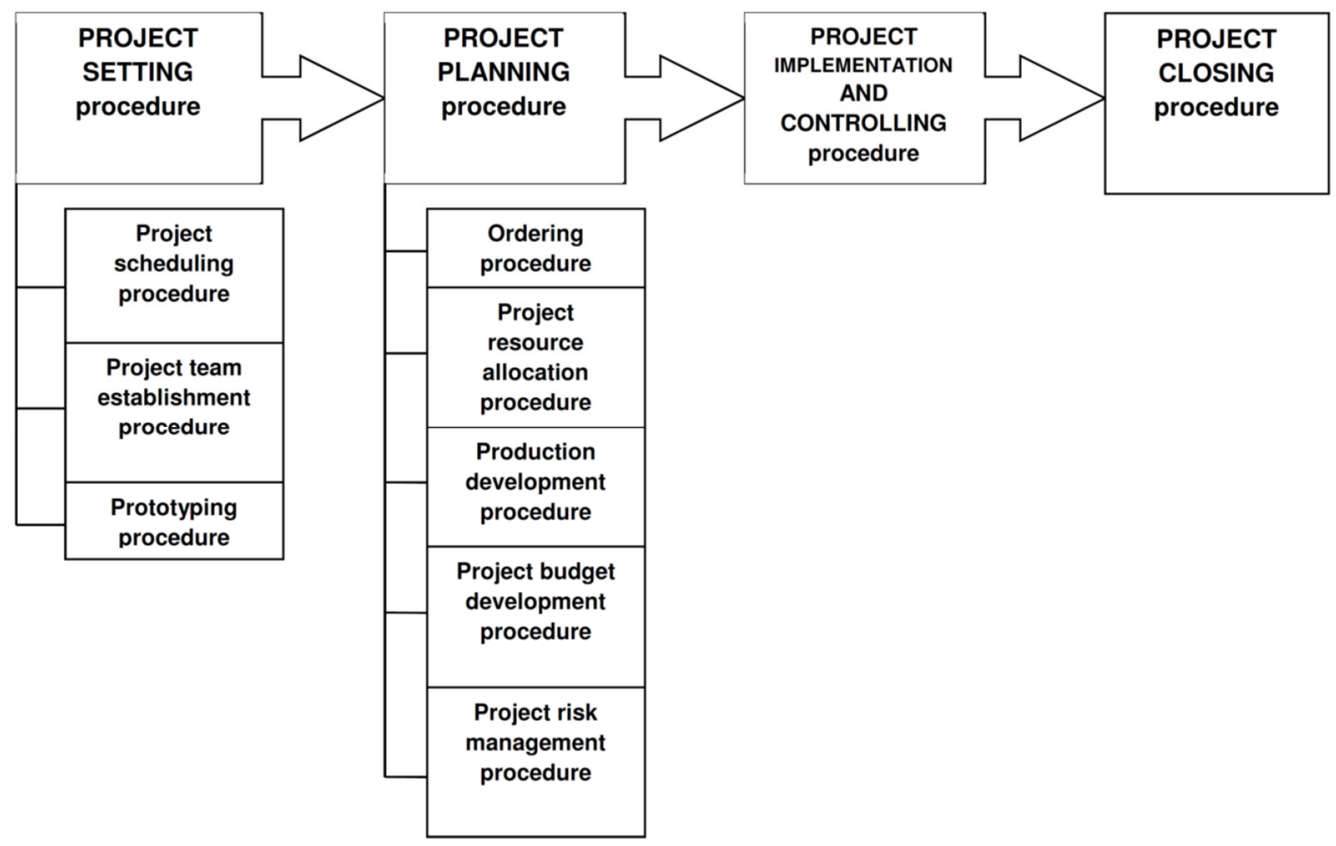

Fig. 2. Application of procedures at different stages of the new product project management process

\section{SUMMARY}

When summarising the considerations presented, one needs to note that the implementation of project management principles, inclusive of new product projects, in the operations of the company selected is carried out by means of developing and implementing a project portfolio management system (PPMS). Within the company, the system is aimed at streamlining new product development and implementation processes as well as order and contract management processes.

To ensure effective implementation of a PPMS in the enterprise, its organisational structure ought to comprise a Project Director, a Project Department, Project Managers and project team members. To ensure effective implementation of the PPMS, implementation procedures carried out by the project team have been developed.

The project portfolio management system has been developed allowing for the conditions of the selected company, its organisational culture, and its management system; it has been implemented and is currently used. Based on the observations carried out, the following recommendations may be formulated:

a) the project portfolio management system within the company needs to be aligned with its functioning, inclusive of its organisational culture and its needs.

b) PPMS development and implementation within the company needs to be supervised by a project director, that preferably being a member of the management board of the company. 
c) in order to efficiently implement the PPMS, several project managers selected from among company employees ought to be prepared for such work.

\section{BIBLIOGRAPHY}

Gembalska-Kwiecień, A. (2017). Development of an innovative methodology supporting project risk management in the manufacturing company of the automotive industry. In: 6th International Conference on Operations Research and Enterprise Systems. ICORES, Porto, Portugal.

Kerzner, H.(2005). Advanced Project Management. Gliwice: Helion.

Kozarkiewicz, A.(2012). Zarządzanie portfelem projektów. Warsaw: PWN.

Spałek, S., Bodych, M. (2012). PMO Praktyka zarządzania projektami i portfelem projektów w organizacji. Gliwice: Helion.

Spałek, S. (2014). The influence of country of origin on project management: an international empirical study. In: E. Gimzauskiene, ed., 19th International Scientific Conference on Economics and Management 2014. ICEM 2014. Amsterdam : Elsevier Science.

Spałek, S. (2016). Traditional vs. modern project management methods. Theory and practice. In: 21st International Scientific Conference on Smart and Efficient Economy - Preparation for the Future Innovative Economy, Brno, Czech Republic.

PMI, A Guide to the Project Management Body of Knowledge (PMBOK®Guide) (2008) - Fourth Edition. Newtown Square.

PRINCE2®: 2009 - 'Effective project management'.

Sońta-Drączkowska, E.(2012). Zarządzanie wieloma projektami. Warsow: PWE.

Stawicki, J. (2009). Zarządzanie portfelem projektów. In: M. Trocki, E. Sońta-Drączkowska, ed., Strategiczne zarządzanie projektami. Warsaw: Wydawnictwo Bizarre.

Trocki, M. (2012). Nowoczesne zarządzanie projektami. Warsaw: PWE. 